\title{
ACUTE EFFECTS OF STATIC AND DYNAMIC STRETCHING ON JUMP PERFORMANCE AFTER 15 MIN OF RECONDITIONING SHOOTING PHASE IN BASKETBALL PLAYERS
}

Giuseppe ANNINO, Bruno RUSCELLO, Pietro LEBONE, Francesco PALAZZO, Mauro LOMBARDO, elvira PADUA, Luca VERDECCHIA, virginia TANCREDI, Ferdinando IELLAMO

J Sports Med Phys Fitness 2015 Dec 03 [Epub ahead of print]

\section{THE JOURNAL OF SPORTS MEDICINE AND PHYSICAL FITNESS}

Rivista di Medicina, Traumatologia e Psicologia dello Sport

pISSN 0022-4707 - elSSN 1827-1928

Article type: Original Article

The online version of this article is located at http://www.minervamedica.it

Subscription: Information about subscribing to Minerva Medica journals is online at: http://www.minervamedica.it/en/how-to-order-journals.php

Reprints and permissions: For information about reprints and permissions send an email to: journals.dept@minervamedica.it - journals2.dept@minervamedica.it - journals6.dept@minervamedica.it 


\section{ACUTE EFFECTS OF STATIC AND DYNAMIC STRETCHING ON JUMP PERFORMANCE} AFTER 15 MIN OF RECONDITIONING SHOOTING PHASE IN BASKETBALL PLAYERS

Running head: Stretching effects after basketball warm-up reconditioning phase.

Giuseppe Annino ${ }^{1,2}$, Bruno Ruscello ${ }^{1}$, Pietro Lebone ${ }^{3}$, Francesco Palazzo ${ }^{1}$, Mauro Lombardo ${ }^{4}$, Elvira

Padua $^{1,4}$, Luca Verdecchia ${ }^{1}$, Virginia Tancredi ${ }^{1,2,4}$ and, Ferdinando Iellamo ${ }^{2,5}$.

1) School of Human Movement Science, University of Rome “Tor Vergata”, Rome, Italy.

2) Department of Systems Medicine, University of Rome “Tor Vergata", Rome, Italy.

3) School of PhD in "Advanced Sciences and Technologies in Rehabilitation Medicine and Sports", University of Rome "Tor Vergata", Rome, Italy.

4) San Raffaele On-Line University, Rome, Italy.

5) I.R.C.C.S. San Raffaele Pisana, Rome, Italy

\section{Corresponding Author:}

Giuseppe Annino,

Department of Systems Medicine, University of Rome “Tor Vergata",

Via Montpellier 1, 00133 Rome, Italy

E-mail: g_annino@hotmail.com 


\section{ABSTRACT}

Aim: to assess the effects of Static (SS) and Dynamic Stretching (DS) on vertical jump performance executed before, immediately after and at the end of the shooting phase (i.e., 15 min later), as to simulate the actual conditions preceding a match, in professional basketball players.

Methods: Ten elite basketball players (age: $29 \pm 6.73$ years, height: $194.67 \pm 7.75 \mathrm{~cm}$, weight: $91 \pm$ 8.17 Kg and BMI $23.8 \pm 7.91 \mathrm{Kg} \cdot \mathrm{m}^{-2}$ ) participated to the study. SS and DS protocols were administered during the first training session of the week, 48 hours after the championship match. Stretching protocols consisted in $\sim 7$ minutes of general warm-up phase followed by $\sim 8$ minutes of SS and DS, performed with a cross-over design., and $\sim 15$ minutes of a specific warm-up shooting phase (SP)

Vertical jump tests consisted in counter movement jump (CMJ) and CMJ with arm swings (CMJas) and were performed immediately after the end of each stretching phase (preS, postS, postSP).

Results: A significant decrease $\left(\mathrm{P}=0.05 ; \eta^{2}\right.$ partial $\left.=0.29\right)$ in jumping tests height occurred in CMJas, when performed after the SS (i.e, PostS). However, no significant differences in jumping performances, occurred after the general warm phase and the specific warm-up shooting phase, between the two stretching protocols

Conclusions: These results would indicate that, overall, stretching routines either dynamic or static, performed before a basketball match are transient and affect only marginally leg muscles performance. Stretching routines, particularly the dynamic ones, may be useful to maintain muscle performance before a competition, provided that this latter begins shortly after.

Key Words: Flexibility; Power; Vertical Jump; Warm-up. 


\section{INTRODUCTION}

Warm-up exercises and stretching performed before training and/or competition are common and wellaccepted practices and there are many scientific evidences supporting their effectiveness $(1,2,3)$.

The warm-up, designed to increase muscles temperature and blood flow and to prepare the body to exercise, has also been shown to affect positively the performance ability $(4,5)$.

Conventional warm-up procedures generally consist in aerobic exercises, upper- and lower- extremity stretching followed by a rehearsal the specific sport skills that will be performed during a match. $(6,7)$. The influence of stretching on sport performance is still a debated issue among athletes, coaches and sport scientists. Some authors believe that the use of stretching, as a part of the warm-up procedures, can actually improve the performance and reduce the risks of muscle injuries $(8,9,10)$, whereas others suggest that stretching might negatively influence the performance $(11,12)$.

In the last decade several studies investigated the effects of static (SS) and dynamic stretching (DS) on jump performance. SS has been reported to negatively affect muscle performance inasmuch as a decrease in maximal force production $(3,4,12,13)$, jumping height $(14,15)$ and sprint velocity $(4,16$, 17) has been observed after this type of stretching and increase in reaction time and impairing in balance $(18,19)$. On the contrary DS, performed as a part of warming-up, has been reported to increase leg extensors muscle power and strength $(12,20,21)$.

Anyway, other aspects of stretching methodologies, such as the optimal duration of stretching protocols and the time that should elapse between a specific stretching routine and the assessment of muscular performance, are still not completely understood $(22,23)$. A meta-analysis by Kay and Blazevich (24) would indicate that although a duration of less of $45 \mathrm{~s}$ for each muscle group does not affect sport performance but a longer duration is capable to reduce it. 
Most of the studies assessing the effects of stretching exercises on muscle performance conducted so far focused on performance assessment done immediately after the end of stretching routines. In many team sports, like basketball, it is customary that the stretching period is followed by a phase of sportspecific drills, of almost 15 minutes duration. In Italy, the rules established by the Basketball Federation, foresee a warm-up phase, whose duration is exactly 30 min before beginning the match. Within this time framework, the warm-up phase usually consists in 7-8 minutes of slow jogging, running, various sprinting and bouncing drills, followed by $\sim 8$ minutes of stretching routines and by $\sim 15$ minutes of a specific shooting phase.

Whether and in which way the time elapsed between stretching exercises and assessment of muscle performance affect the latter is not completely defined.

Accordingly, this study was designed to assess the effects of SS and DS on vertical jump performance executed before, immediately after and at the end of the shooting phase (i.e., 15 min later), as to simulate the actual conditions preceding a match, in professional basketball players.

We hypothesized that after the shooting phase of warm-up both SS and DS have no detectable effects on skeletal muscle power performance, as assessed by a vertical jump test. 


\section{METHODS}

\section{Experimental Approach to the problem}

The experimental procedure is summarized in Figure 1.

Testing procedures were performed during the competitive season in an indoor sport court made with a wooden surface. Experiments were performed during the first training session of the week, so that the players had an adequate resting time that is $\sim 48$ hours after the championship match.

All subjects were familiar with these stretching protocols, warm-up exercises and performance tests. Subjects performed a 7-8 minutes general warm-up, consisting of slow jogging, running, various sprinting and bouncing drills (i.e. high knees, butt kicks, skips, vertical jumps), carioca, lateral shuffle and backwards reaching runs.

Immediately after the general warm-up phase, participants completed a set of 3 maximal-effort jump tests (CMJpreS).

Both the stretching protocols were administrated to the subjects in a crossover study.

Following the tests, the players were randomly assigned to two stretching groups: SS and DS. Both stretching protocols involved the same muscle groups and had a total duration of $\sim 8$ minutes. At the end of this phase a vertical jump test was performed again (CMJpostS). The pre-match warm-up protocol continued with a 15 minutes shooting phase, in which one player shot the ball from anywhere on the court, at increasing intensity in the last 3-4 minutes during which all players performed also the slam dunks until the end of warm-up, after which a further vertical jump test was performed (CMJpostSP).

Accordingly to the crossover design of the study, in the subsequent week the two players groups switched the protocol, in order to avoid that the order of both protocols could influence the results. 


\section{Subjects}

This study was conducted on ten subjects (age: $29 \pm 6.73$ years, $194.67 \pm 7.75 \mathrm{~cm}$, weight: $91 \pm 8.17$ and BMI $23.8 \pm 7.91 \mathrm{~kg} \cdot \mathrm{m}^{-2}$ ), affiliated with a professional club competing in the Italian National Federal League level 2 basketball championship. The players usually trained five times per week for $\sim 2$ hours per session, plus a competitive match that took place during the weekend.

Written informed consent was obtained from all the participants after familiarization and explanation of the benefit and risks involved in the procedures of this study. All participants were informed that they were free to withdraw from the study at any time without penalty. The study was approved by the Institutional Research Board (the Ethical Committee of the School of Sports and Exercise Science, University of Rome "Tor Vergata", Faculty of Medicine and Surgery). All procedures were carried out in accordance with the Declaration of Helsinki of the World Medical Association as regards the conduct of clinical research.

All participants were healthy, free from injury and without any physical problem that could affect the test results.

During all the experimental sessions, the players were asked to wear the same shoes and sportswear; they were given standardized instructions about the procedures and verbal encouragements to perform the tests to the best of their ability.

The participants were not allowed to see the results until the study was completed.

\section{Vertical Jump Test}

The players performed two types of jump test: the Counter Movement Jump test (CMJ) and the Counter Movement Jump test with arms swing (CMJas).

The jumps started in the standing posture, keeping the hands on the waist, and after an eccentric action of the knee and hip extensors, with which $90^{\circ}$ of knee flexion position is reached; a concentric 
contraction phase then followed that rapidly extended the knees before take-off. The other jump test was performed in the same way but inserting the swing of the arms (CMJas).

Participants were instructed to perform $3 \mathrm{CMJ}$ and $3 \mathrm{CMJ}$ as with a maximum effort, jumping as high as possible. A 60 -second recovery period was allowed between each jump (25).

The performance of each jump was assessed using a contact mat (Ergojump, Bosco System, Italy) with by which the flight time and consequently the jump height to the nearest centimetre is automatically calculated according to Eq. 1 (26):

$$
\boldsymbol{h}=\boldsymbol{t} \boldsymbol{f}^{2} \cdot \boldsymbol{g} \cdot \boldsymbol{8}^{-1} \quad \mathrm{Eq} \cdot 1
$$

where $\mathrm{tf}$ is the fly time of the jump and $\mathrm{g}$ is the gravitational constant $\left(9.81 \mathrm{~m} \cdot \mathrm{s}^{-2}\right)$. The best CMJ and CMJas were chosen for the statistical analysis. The reproducibility of the CMJ testing procedure utilized in the present investigation has been reported to be high $(26,27,28)$.

\section{Stretching Protocol}

For this study two types of stretching were used: static (SS) and dynamic stretching (DS).

The SS protocol included two exercises for the extensor muscles of the legs and hip flexor, three exercises for the flexor muscles of the lower limbs (Hamstring group: Biceps femoris, Semimembranosus, Semitendinosus), two exercises for the adductors muscles (Sartorius, Gracilis and Adductors muscles), and one exercises for the gastrocnemius muscle.

The SS protocol consisted in a 8-minutes of static stretching, in standing or sitting position, emphasizing the lower-extremity muscle groups (Table I). This is the usual time spent by the players in a warm-up period preceeding the beginning of a match. The technique of the SS required the subjects to slowly take up to the point of maximal muscular tension and hold for a period of 30 seconds, for each muscular group. A 30 seconds period was selected because this duration is typically used by the players. Each exercise was repeated one time, for each leg. 
The DS protocol consisted in a 8-minutes of low-intensity walking in the half court followed by dynamic stretching emphasizing the same muscle groups included in the SS protocol (Table II). The dynamic movements progressed from moderate to high intensity. The technique of the dynamic stretching required the subject to maintain an upright posture. Subjects performed each dynamic exercise three times, walking over a distance of 15 meters, and repeating the exercise with alternating legs, every three steps.

Stretching protocols were performed immediately after the 8-minutes general warm-up and the first set of jumping tests.

Stretch protocols were supervised by a qualified sport specialist. At the end of each stretching protocol, the subjects performed the second jumping test.

In the subsequent week the two groups switched the stretching protocols, according to the cross-over study design.

\section{Statistical Analysis}

Descriptive statistics (mean $\pm \mathrm{SD} ; 95 \%$ CIs) were computed and provided for the dependent variable (the best performance reached in jumping tests as the maximum height recorded); the assumption of normality was confirmed through the Shapiro-Wilk test. The Intraclass Correlation Coefficients (ICC) for single measure are provided as indices of relative reliability of the tests (Table.III).

To identify significant differences within the sample for each stretching protocol investigated (SS and DS), an analysis of variance for repeated measures was performed. Paired t-tests were performed to assess the differences among the considered protocols (SS vs DS) within the sample when performing the jump tests: preS, postS and postSP, respectively. The effect size (ES) was also calculated (ref Cohen). Absolute ES of $0.20,0.50$ and 0.80 represented small, medium and large differences, respectively. 
To test the main effect and the interactions between factors (type of stretching as independent variables, the CMJ best performance for each investigated phase as a dependent variable) an analysis of variance, for repeated measures, was performed. ( 2 x 3, stretching protocols for warm-up phases). After performing the Mauclhy test of sphericity, the Greenhouse-Geisser, was used when appropriate. Bonferroni-adjusted 1-tailed paired t-tests post hoc analyses were used to locate the differences between the stretching protocols if significant main effect for stretching or warm-up phases were found. ES in ANOVA was computed as partial $\eta^{2}$, according to Cohen (1988), to assess meaningfulness of differences, with $\eta^{2}<0.01,0.01<\eta^{2}<0.06,0.06<\eta^{2}<0.14$ and $\eta^{2}>0.14$, as trivial, small, moderate and large ES, respectively.

The corresponding $p$ values are provided for each analysis. IBM - SPSS 20.0 for Windows (SPSS, Inc. Chicago. IL, USA) was used for statistical analysis. Statistical significance was set at $P<0.05$.

\section{RESULTS}

Results of CMJ tests, performed in a standard mode (i.e. with blocked arms) and with the arms swing, are reported in Table IV and V. No statistically significant differences were found in CMJ after SS $\left(P=0.14\right.$; ES as $\eta^{2}$ partial $=0.20$; power 0.30, with adjustment Greenhouse-Geisser) (Fig. 2). On the contrary, the CMJas tests showed a significant difference between warm-up phases $(P<0.05$; ES as $\eta^{2}$ partial $=0.29$; power 0.60). Post-hoc analysis showed statistically significant differences between the values recorded in SS CMJas post-stretching and SS CMJas post-shooting phase $(P<0.05)$ (Fig. 3). DS did not significantly affect both $\mathrm{CMJ}\left(P=0.55\right.$; ES as $\eta^{2}$ partial $=0.06$; power 0.14$)$ and $\mathrm{CMJas}(\mathrm{P}=0.32$; ES as $\eta_{\text {partial }}^{2}=0.19$; power $\left.0.23,=0.05\right)$. No significant differences were found between the jumping performance, measured by CMJ performed in both different modes and stretching methods. 


\section{DISCUSSION}

The main finding of this study is that, overall, stretching routines either dynamic or static, performed before a match, are transient and affect only marginally leg muscles performance. This would indicate that stretching routines, particularly the dynamic ones, are useful to maintain muscle performance before a competition, provided that this latter begins shortly after.

The issue of stretching routines before the beginning of an athletic task is highly debated. In particular, the effectiveness of static stretching has been questioned in the last decade. In fact, several studies reported a negative effect of SS on performance $(4,7,15,29,30,31)$ that has been ascribed to a combination of mechanical $(16,30,32,33,34)$ and neurological factors $(19,29,32,35)$. In keeping with these studies, we observed a significant decrease in performance after SS, particularly in CMJas. From the mechanical point of view, SS would compromise muscle performance by the way of reduced musculotendinous unit (MTU) stiffness $(16,30,36)$ and decreased muscle activation $(32,33)$ whereas from a neurological standpoint neuromuscular reflexes and motor unit activation would decrease (19, 32, 35). However, the modest decrease in CMJas disappeared after the shooting phase, becoming not significantly different from DS, although a trend towards an improvement in performance after DS was observed (Fig. 2), in keeping with previous studies $(6,15,20,37)$. The improvement after DS has been ascribed to several factors such as the increase of the core temperature, the enhanced sensitivity of nerve receptors, the speed of the nervous impulses (5) and to rehearsal of movement coordination (4). A novelty of the present investigation is that we assessed jump height performances 15 minutes after the end of SS and DS, whereas most of previous studies examined muscular performance immediately after the end of stretching routines, without taking into account the possible effect of the time elapsed from stretching on performance.

The results of our study are in agreement with those of Bradley et al. (29), who reported a return of vertical jump performance to base-line values 15 minutes after all stretching routines (i.e., SS and DS).

This document is protected by international copyright laws. No additional reproduction is authorized. It is permitted for personal use to download and save only one file and print only one copy of this Article. It is not permitted to make additional copies (either sporadically or systematically, either printed or electronic) of the Article for any purpose. It is not permitted to distribute the electronic copy of the article through online internet and/or intranet file sharing systems, electronic mailing or any other means which may allow access to the Article. The use of all or any part of the Article for any Commercial Use is not permitted. The creation of derivative works from the Article is not permitted. The production of reprints for personal or commercial use is no frame or use framina techniaues to enclose any trademark, loao, or other proprietary information of the Publisher. 
They are also in line with the findings of Woolstenhulme et al. (31) who reported no differences in VJ height performed immediately after the SS and DS. A confirmation of the transient effect of stretching comes from a recent study by Mizuno et al. (38) in which the decrease in MTU stiffness observed after 5 min of SS disappeared spontaneously within 10 minutes.

\section{CONCLUSION}

On the basis of our findings, we cannot recommend a specific type of stretching for improving muscular performance because of its short-lasting effect, at least in male basketball players. However, the short-lasting decreasing of muscle performance we observed 8 minutes after SS would suggest that the DS is the preferable one for maintenance of warming and reducing the viscosity of the myotendinuous and articular structures when the competition begins shortly after. 


\section{REFERENCE}

1) Bishop D. Warm up II: Performance changes following active warm up and how to structure the warm up. Sport. Med 2003; 33: 483-498,.

2) Faigenbaum AD, Kang J, McFarland J, Bloom JM, Magnatta J, Ratamess NA, Hoffman J. Acute Effects of Different Warm-Up Protocols on Anaerobic Performance in Teenage Athletes. Pediatr. Exerc. Sci 2006; 18: 64-75.

3) McMillian DJ, Moore JH, Hatler BS, Taylor DC. Dynamic vs. static-stretching warm up: the effect on power and agility performance. J. Strength Cond. Res 2006; 20: 492-499.

4) Fletcher IM and Jones B. The effect of different warm-up stretch protocols on 20 meter sprint performance in trained rugby union players. J. Strength Cond. Res 2004; 18(4): 885-888.

5) Shellock FG and Prentice WE. Warming-up and stretching for improved physical performance and prevention of sports-related injuries. Sports Med 1985; 2(4): 267-278.

6) Needham RA, Morse CI, Degens H. The acute effect of different warm-up protocols on anaerobic performance in elite youth soccer players. J. Strength Cond. Res 2009; 23(9): 2614-2620.

7) Young WB and Behm DG. Should Static Stretching Be Used During a Warm-Up for Strength and Power Activities? Strength Cond. J 2002; 24(6): 33.

8) Knudson DV, Noffal GJ, Bahamonde RE, Bauer JA, Blackwell JR. Stretching has no effect on tennis serve performance. J. Strength Cond. Res 2004; 18(3): 654-656.

9) Shrier I and Gossal, K. Myths and truths of stretching: individualized recommendations for healthy muscles. Phys. Sportsmed 2000; 28(8): 57-63.

This document is protected by international copyright laws. No additional reproduction is authorized. It is permitted for personal use to download and save only one file and print only one copy of this Article. It is not permitted to make additional copies (either sporadically or systematically, either printed or electronic) of the Article for any purpose. It is not permitted to distribute the electronic copy of the article through online internet and/or intranet file sharing systems, electronic mailing or any other means which may allow access to the Article. The use of all or any part of the Article for any Commercial Use is not permitted. The creation of derivative works from the Article is not permitted. The production of reprints for personal or commercial use is not permitted. It is not permitted to remove, cover, overlay, obscure, block, or change any copyright notices or terms of use which the Publisher may post on the Article. It is not permitted to frame or use framina techniques to enclose any trademark, logo, or other proprietary information of the Publisher. 
10) Shrier I. Does stretching improve performance? A systematic and critical review of the literature. Clin. J. Sport Med 2004; 14(5): 267-273.

11) Bacurau RFP, Monteiro GA, Ugrinowitsch C, Tricoli V, Cabral LF, Aoki MS. Acute effect of a ballistic and a static stretching exercise bout on flexibility and maximal strength. J. Strength Cond. Res 2009; 23(1): 304-308.

12) Yamaguchi $T$ and Ishii $K$. Effects of static stretching for 30 seconds and dynamic stretching on leg extension power. J. Strength Cond. Res 2005; 19(3): 677-683.

13) Cramer JT, Housh TJ, Weir JP, Johnson GO, Coburn JW, Beck TW. The acute effects of static stretching on peak torque, mean power output, electromyography, and mechanomyography. Eur. J. Appl. Physiol 2005; 93(5-6): 530-539.

14) Behm DG, Bradbury EE, Haynes AT, Hodder JN, Leonard AM, Paddock NR. Flexibility is not Related to Stretch-Induced Deficits in Force or Power. J. Sports Sci. Med 2006; 5(1): 33-42.

15) Young WB and Behm DG. Effects of running, static stretching and practice jumps on explosive force production and jumping performance. J. Sports Med. Phys. Fitness 2003; 43(1): 21-27.

16) Nelson AG, Kokkonen J, Arnall DA. Acute muscle stretching inhibits muscle strength endurance performance. J. Strength Cond. Res 2005; 19(2): 338-343.

17) Winchester JB, Nelson AG, Landin D, Young MA, Schexnayder IC. Static stretching impairs sprint performance in collegiate track and field athletes. J. Strength Cond. Res 2008; 22(1): 13-19.

18) Behm DG, Bambury A, Cahill F, Power K. Effect of Acute Static Stretching on Force, Balance, Reaction Time, and Movement Time. Med. Sci. Sport. Exerc 2004; 36(8): 1397-1402.

19) Kirmizigil B, Ozcaldiran B, Colakoglu M. Effects of three different stretching techniques on copy of this Article. It is not permitted to make additional copies (either sporadically or systematically, either printed or electronic) of the Article for any purpose. It is not permitted to distribute the electronic copy of the article through online internet and/or intranet file sharing systems, electronic mailing or any other means which may allow access to the Article. The use of all or any part of the Article for any Commercial Use is not permitted. The creation of derivative works from the Article is not permitted. The production of reprints for personal or commercial use is not frame or use framina techniques to enclose any trademark, logo, or other proprietary information of the Publisher. 
vertical jumping performance. J. Strength Cond. Res 2014; 28(5): 1263-1271.

20) Perrier ET, Pavol MJ, Hoffman MA. The acute effects of a warm-up including static or dynamic stretching on countermovement jump height, reaction time, and flexibility. J. Strength Cond. Res 2011; 25(7): 1925-1931.

21), Thompsen AG, Kackley T, Palumbo MA, Faigenbaum AD. Acute effects of different warm-up protocols with and without a weighted vest on jumping performance in athletic women. J. Strength Cond. Res 2007; 21(1):52-56.

22) Avela J, Finni T, Liikavainio T, Niemela E, Komi PV. Neural and mechanical responses of the triceps surae muscle group after $1 \mathrm{~h}$ of repeated fast passive stretches. Journal of Applied Physiology 2004; 96: 2325-2332.

23) Moss WR, Feland JB, Hunter I, Hopkins JT. Static stretching does not alter pre and post-landing muscle activation. Sports Med. Arthrosc. Rehabil. Ther. Technol 2011;3(1): 9.

24) Kay $\mathrm{AD}$ and Blazevich $\mathrm{AJ}$. Effect of acute static stretch on maximal muscle performance: a systematic review. Med Sci Sports Exerc 2012; 44(1):154-64.

25) Read MM and Cisar C. The influence of varied rest interval lengths on depth jump performance. J. Strength Cond. Res 2001; 15(3): 279-283.

26) Bosco C, Luhtanen P, Komi PV. A simple method for measurement of mechanical power in jumping. Eur. J. Appl. Physiol 1983; 50: 273-282.

27) Bosco C, Komi PV, Ito A. Prestretch potentiation of human skeletal muscle during ballistic movement. Acta Physiol. Scand 1981; 111(2): 135-140.

28) Buckthorpe M, Morris J Folland JP. Validity of vertical jump measurement devices. J Sports Sci

This document is protected by international copyright laws. No additional reproduction is authorized. It is permitted for personal use to download and save only one file and print only one copy of this Article. It is not permitted to make additional copies (either sporadically or systematically, either printed or electronic) of the Article for any purpose. It is not permitted to distribute the electronic copy of the article through online internet and/or intranet file sharing systems, electronic mailing or any other means which may allow access to the Article. The use of all or any part of the Article for any Commercial Use is not permitted. The creation of derivative works from the Article is not permitted. The production of reprints for personal or commercial use is not frame or use framina techniques to enclose any trademark logo, or other or change any copyright notices or terms of use which the Publisher may post on the Article. It is nol permitted to 
2012; 30(1): 63-9.

29) Bradley P, Olsen P, Portas M. The effect of static, ballistic, and proprioceptive neuromuscular facilitation stretching on vertical jump performance. J. Strength Cond. Res 2007; 21(1): 223-226.

30) Nelson AG and Kokkonen J. Acute ballistic muscle stretching inhibits maximal strength performance. Res. Q. Exerc. Spor 2001; 72(4): 415-419.

31) Woolstenhulme MT, Griffiths CM, Woolstenhulme EM, Parcell AC. Ballistic stretching increases flexibility and acute vertical jump height when combined with basketball activity. J. Strength Cond. Res 2006; 20(4): 799-803.

32) Behm DG, Button DC, Butt JC. Factors affecting force loss with prolonged stretching. Can. J. Appl. Physiol 2001; 26(3): 261-272.

33) Cornwell A, Nelson AG, Sidaway B. Acute effects of stretching on the neuromechanical properties of the triceps surae muscle complex. Eur. J. Appl. Physiol 2002; 86(5): 428-434.

34) Witvrouw E, Mahieu N, Danneels L, McNair P. Stretching and injury prevention: an obscure relationship. Sports Med 2004; 34(7): 443-449.

35) Avela J, Kyröläinen H, Komi PV. Altered and reflex sensitivity after repeated and prolonged passive muscle stretching. J. Appl. Physiol 1999; 86(4):1283-1291.

36) Nelson AG, Guillory IK, Cornwell C, Kokkonen J. Inhibition of maximal voluntary isokinetic torque production following stretching is velocity-specific. J. Strength Cond. Res 2001; 15(2): 241246.

37) Carvalho FL, Carvalho MC, Simão R, Gomes TM, Costa PB, Neto LB, Carvalho RL, Dantas EH. Acute effects of a warm-up including active, passive, and dynamic stretching on vertical jump 
performance. J. Strength Cond. Res 2012; 26(9): 2447-2452.

38) Mizuno T, Matsumoto M, Umemura Y. Decrements in stiffness are restored within 10 min. Int. J. Sports Med 2013; 34(6):,484-490. 
FIGURE and TABLES LEGENDS

Figure 1. Experimental design - cross over study.

Figure 2. Vertical jump performance in the CMJ pre stretching (preS), post stretching (postS), post specific shooting phase (postSP) in SS and DS protocol. No statistical difference was found between stretching protocols and warm-up phases.

Figure 3. Vertical jump performance in the CMJas pre stretching (preS), post stretching (postS), post specific shooting phase (postSP) in SS and DS protocol. Statistical difference was found in SS between postS and postSP $(P=.05)$.

Table I. Static Stretching Protocol. Each stretching positions were held for 30 seconds each for each lower extremity.

Table II. Dynamic Stretching Protocol. Each exercise was performed walking half a basketball court three times each way

Table III. Intraclass Correlation Coefficient (ICC) for each test

Table IV. Descriptive Statistics of CMJ results $(\mathrm{cm})$

Table V. Descriptive Statistics of CMJas results $(\mathrm{cm})$. 
TABLE I.

\begin{tabular}{|c|c|c|}
\hline Muscle & Stretch & Description \\
\hline \multirow{2}{*}{$\begin{array}{c}2 \text { exercise for } \\
\text { extensor muscles }\end{array}$} & $\begin{array}{l}\text { Standing quadriceps } \\
\text { stretch }\end{array}$ & $\begin{array}{l}\text { In standing position, subject flexes } 1 \text { knee and grasps the ankle, } \\
\text { bringing the heel as close as possible to the buttocks. Subject } \\
\text { repeats the exercise with the opposite leg. }\end{array}$ \\
\hline & Hip flexor stretch & $\begin{array}{l}\text { From a lunge position, subject with vertical trunk, slowly lowers } \\
\text { and pushes forward the hips until the front knee is flexed to } \\
90 \text { and the back leg is extended. Same procedure is carried out } \\
\text { with opposite leg. }\end{array}$ \\
\hline \multirow{3}{*}{$\begin{array}{c}3 \text { exercise for flexor } \\
\text { muscle }\end{array}$} & Standing straddle & $\begin{array}{l}\text { Standing with feet apart in a straddle position. Subject leans } \\
\text { forward bringing his chest toward his right knee, grasping the } \\
\text { ankle and keeping his back flat until a slight tension is felt in } \\
\text { hamstring. Hold } 20 \text { seconds and he repeats the exercise for } \\
\text { the left leg. }\end{array}$ \\
\hline & Crossed leg stretch & $\begin{array}{l}\text { Standing with legs crossed, subject leans forward bringing his } \\
\text { hands down toward feet, until the hamstring is stretched. } \\
\text { Subject repeats the exercise with the opposite leg. }\end{array}$ \\
\hline & $\begin{array}{l}\text { Sitting Single Leg } \\
\text { Hamstring Stretch }\end{array}$ & $\begin{array}{l}\text { Subject sits down with the right leg straight out in front and the } \\
\text { left leg bended with the sole of the foot alongside the right } \\
\text { knee. Subjects leans forward towards right toes, keeping the } \\
\text { back straight. Subject repeats the exercise with the other leg. }\end{array}$ \\
\hline 2 exercise for & Lateral lunge & $\begin{array}{l}\text { In standing position, subject steps out to the right side, shifting his } \\
\text { body weight over the right leg and keeping his left leg straight. } \\
\text { Squat as low as possible until a slight stretch is felt in } \\
\text { hamstring. Subject goes back to the starting position and } \\
\text { repeats the exercise on the left side. }\end{array}$ \\
\hline
\end{tabular}

Butterfly (groin) stretch

From a seated position, participants brought the soles of their feet together and allowed their knees to hang to the sides. Gentle pressure was exerted by the elbows to lower the knees toward the ground.

Subject stands with one leg in front of the other and hands on the

1 exercise for gastrocnemius muscle
Calf wall stretch wall. Subject leans forward and slightly flexes front knee. At the same time, subject extends back knee while keeping that heel in contact with floor until subject feels a slight stretch in calf of back leg. Same procedure is carried out with opposite leg. 
TABLE II.

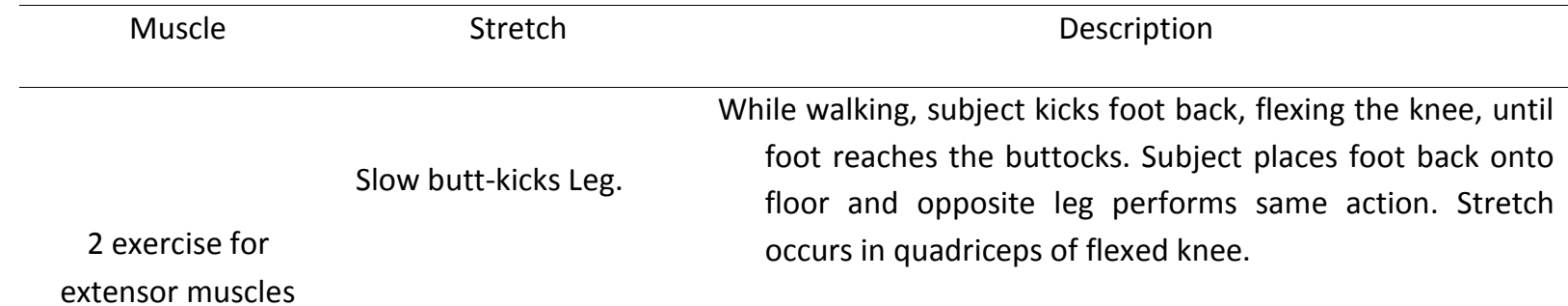

Forward lunge with While walking, subject performs a forward lunge with one opposite arm reach leg, bringing the opposite arm lying upwards and keeping upward. his back flat until a slight tension is felt in quadriceps.

\begin{tabular}{|c|c|c|}
\hline \multirow{3}{*}{$\begin{array}{l}3 \text { exercise for flexor } \\
\text { muscle }\end{array}$} & Forward leg extension. & $\begin{array}{l}\text { While walking, every three steps, subject rises up the knee to } \\
\text { the chest extending the same leg forward. }\end{array}$ \\
\hline & $\begin{array}{l}\text { Leg swing to opposite } \\
\text { hand. }\end{array}$ & $\begin{array}{l}\text { While walking, subject takes a step with right leg while } \\
\text { swinging left leg forward. Left leg touches right hand } \\
\text { while keeping the knee extended. This leg is then brought } \\
\text { down to floor and opposite leg performs same action. } \\
\text { Stretch occurs in hamstrings of swinging leg. }\end{array}$ \\
\hline & $\begin{array}{l}\text { Forward lunge with } \\
\text { opposite arm reach } \\
\text { downward. }\end{array}$ & $\begin{array}{l}\text { While walking, subject performs a forward lunge with one } \\
\text { leg, reaching with the opposite arm the front foot toe. }\end{array}$ \\
\hline \multirow[t]{2}{*}{$\begin{array}{l}2 \text { exercise for } \\
\text { adductors muscle }\end{array}$} & $\begin{array}{l}\text { Hurdler's knee raises } \\
\text { forward movement. }\end{array}$ & $\begin{array}{l}\text { While traveling forward, the participant raises the trailing leg } \\
\text { and places the hip in flexion }\left(\sim 90^{\circ}\right) \text { in an abducted and } \\
\text { externally rotated position, with the knee flexed at } 90^{\circ} \text {. In } \\
\text { this position, the limb is displaced forward as though the } \\
\text { participants were stepping over an object just below } \\
\text { waist height and returned to the normal walking stride } \\
\text { position. }\end{array}$ \\
\hline & Lateral low shuffle. & $\begin{array}{l}\text { From standing position, subject performs a lateral low shuffle } \\
\text { alternating every three steps a lateral lunge (one for each } \\
\text { leg). }\end{array}$ \\
\hline $\begin{array}{l}1 \text { exercise for } \\
\text { gastrocnemius } \\
\text { muscle }\end{array}$ & Tip-toe walking. & $\begin{array}{l}\text { Traveling forward while completing alternating plantar } \\
\text { flexion (tip toe) with every step forward. The aim is to } \\
\text { raise the body as high as possible through tip toeing. }\end{array}$ \\
\hline
\end{tabular}
This document is protected by international copyright laws. No additional reproduction is authorized. It is permitted for personal use to download and save only one file and print only one
copy of this Article. It is not permitted to make additional copies (either sporadically or systematically, either printed or electronic) of the Article for any purpose. It is not permitted to distribute the electronic copy of the article through online internet and/or intranet file sharing systems, electronic mailing or any other means which may allow access to the Article. The use of all or any
the the electronic copy of the article through online internet and/or intranet file shaning systems, electronic mailing or any other means which may allow access to the Article. The use of all or any
part of the Article for any Commercial Use is not permitted. The creation of derivative works from the Article is not permitted. The production of reprints for personal or commercial use is not part of the Article for any Commercial Use is not permitted. The creation of derivative works from the Article is not permitted. The production of reprints for personal or commercial use is not
permitted. It is not permitted to remove, cover, overlay, obscure, block, or change any copyright notices or terms of use which the Publisher may post on the Article. It is not permitted to frame or use framina techniques to enclose any trademark, logo, or other proprietary information of the Publisher. 
Table III

Test

ICC

95\% Confidence Interval

$p$

(Single Measure)

\begin{tabular}{lccc}
\hline Static Stretching (SS) & 0.855 & $0.65-0.96$ & $<0.001$ \\
Dynamic Stretching (DS) & 0.912 & $0.77-0.97$ & $<0.001$
\end{tabular}

This document is protected by international copyright laws. No additional reproduction is authorized. It is permitted for personal use to download and save only one file and print only one copy of this Article. It is not permitted to make additional copies (either sporadically or systematically, either printed or electronic) of the Article for any purpose. It is not permitted to distribute the electronic copy of the article through online internet and/or intranet file sharing systems, electronic mailing or any other means which may allow access to the Article. The use of all or any part of the Article for any Commercial Use is not permitted. The creation of derivative works from the Article is not permitted. The production of reprints for personal or commercial use is not permitted. It is not permitted to remove, cover, overlay, obscure, block, or change any copyright notices or terms of use which the Publisher may post on the Article. It is not permitted to frame or use framina techniques to enclose any trademark, logo, or other proprietary information of the Publisher. 


\section{Table IV}

95\% Confidence Interval for Mean

Mean Std. Dev. Std. Error Lower Bound Upper Bound

\begin{tabular}{lccccc}
\hline SS CMJ pre & 38.75 & 3.12 & 0.99 & 36.52 & 40.98 \\
\hline DS CMJ pre & 38.97 & 3.55 & 1.12 & 36.42 & 41.51 \\
\hline SS CMJ postS & 38.23 & 2.77 & 0.88 & 36.24 & 40.22 \\
\hline DS CMJ postS & 39.18 & 4.96 & 1.57 & 35.63 & 42.73 \\
\hline SS CMJ postSP & 39.22 & 2.84 & 0.90 & 37.18 & 41.25 \\
\hline DS CMJ postSP & 39.60 & 4.13 & 1.30 & 36.64 & 42.55
\end{tabular}

$\mathrm{SS}=$ Static Stretching; DS=Dynamic Stretching 
Table V

$95 \%$ Confidence Interval for Mean

Mean Std. Dev. Std. Error Lower Bound Upper Bound

\begin{tabular}{lccccc}
\hline SS CMJ as pre & 45.85 & 3.43 & 1.08 & 43.40 & 48.30 \\
\hline DS CMJ as pre & 46.16 & 4.25 & 1.34 & 43.11 & 49.20 \\
\hline SS CMJ as postS & 45.02 & 3.73 & 1.18 & 42.35 & 47.70 \\
\hline DS CMJ as postS & 46.32 & 5.01 & 1.58 & 42.74 & 49.90 \\
\hline SS CMJ as postSP & 46.48 & 3.70 & 1.17 & 43.83 & 49.13 \\
\hline DS CMJ as postSP & 46.90 & 4.60 & 1.45 & 43.60 & 50.19
\end{tabular}

$\mathrm{SS}=$ Static Stretching; DS=Dynamic Stretching 
Figure 1.

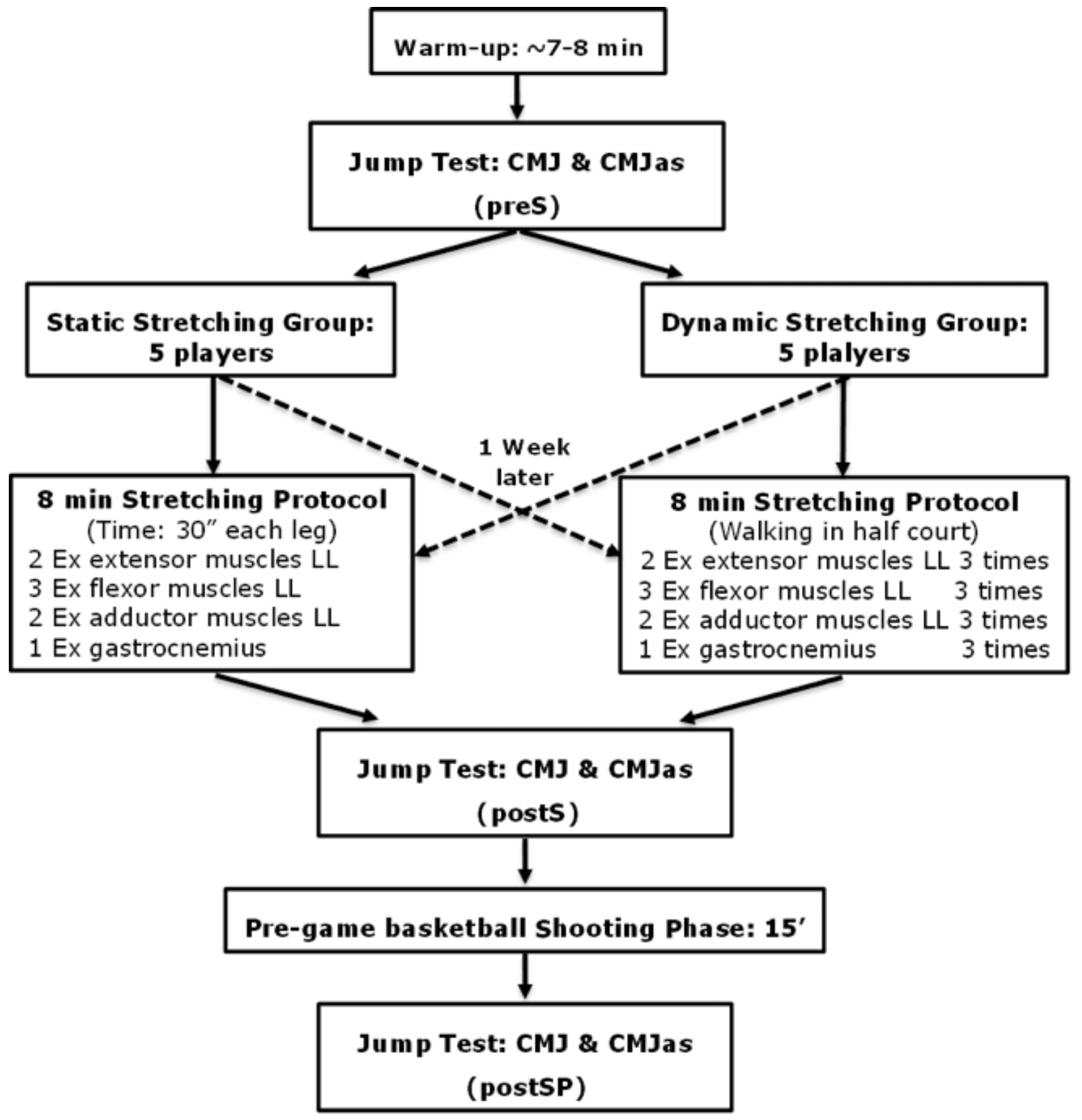


Figure 2.

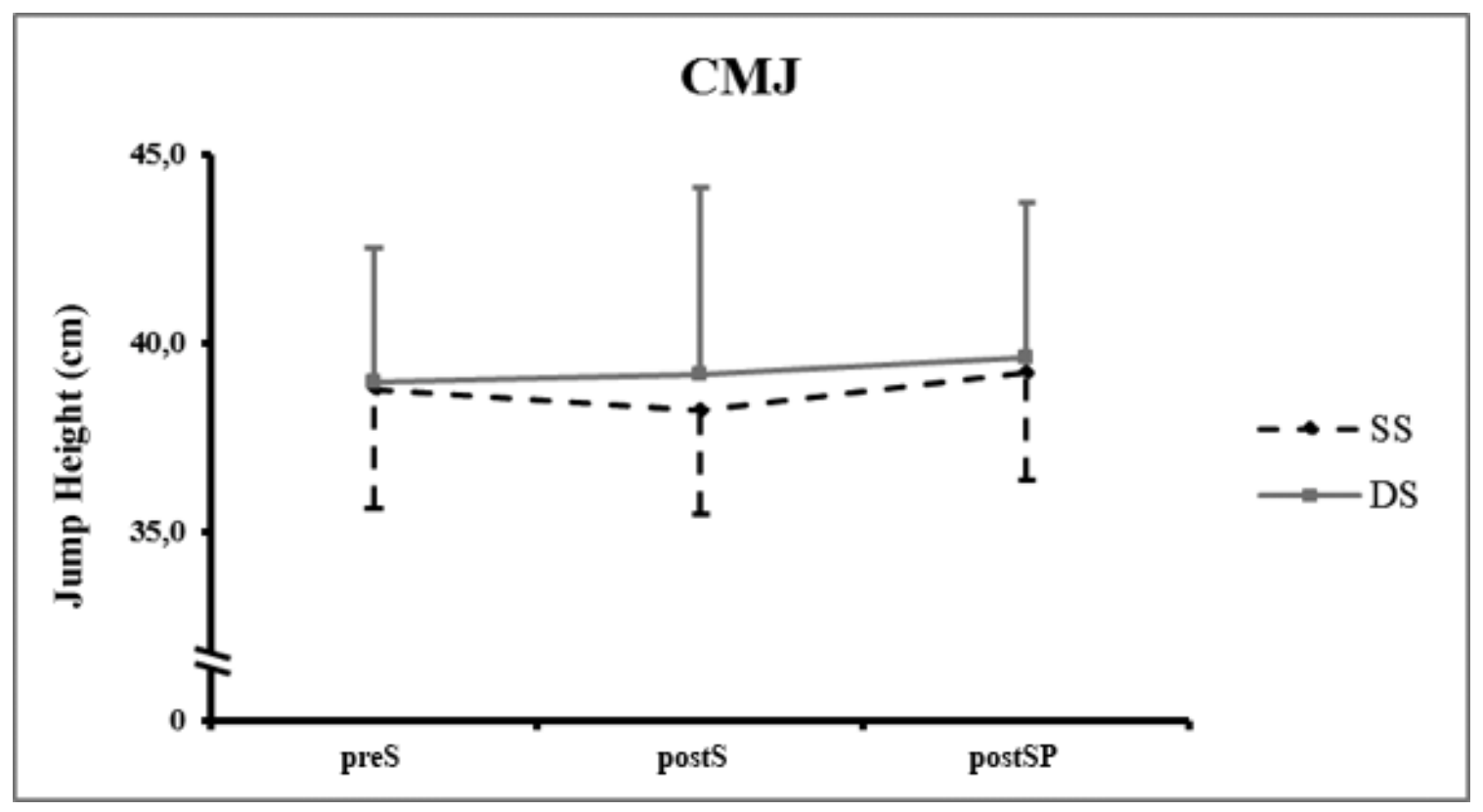


Figure 3.

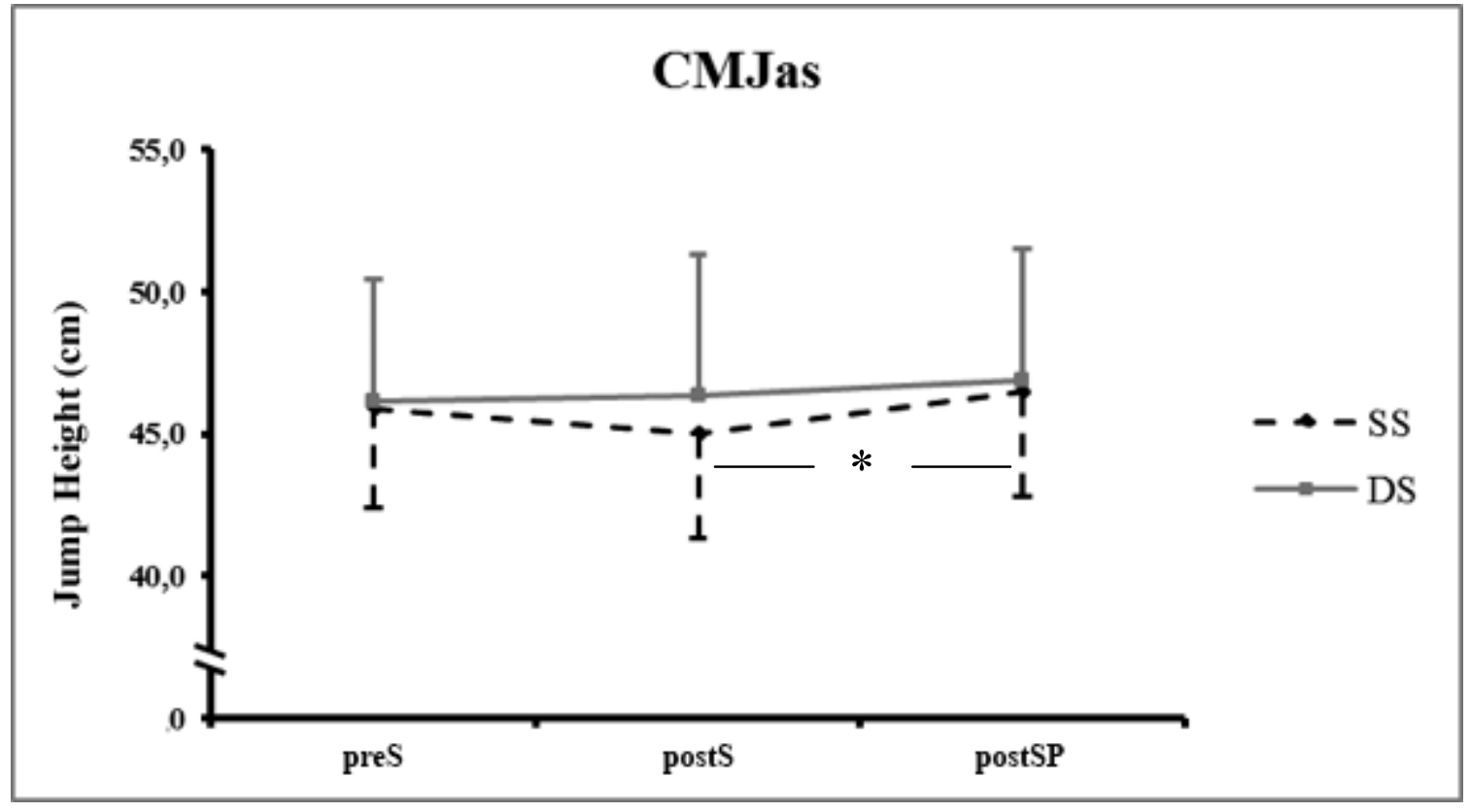

